\title{
Lithics in the Land of the Lightning Brothers: The Archaeology of Wardaman Country, Northern Territory
}

Chris Clarkson

Canberra: Australian National University E Press, 2007, 238 pp. (paperback), \$49.50.

ISBN-13: 9781921313288.

\section{Reviewed by SAM C. LIN}

Department of Anthropology, Penn Museum, 3260 South Street, University of Pennsylvania, Philadelphia, PA 19104, USA; samlin@sas.upenn.edu

$\mathrm{C}$ larkson's book is based on his 2004 doctoral research on stone tool assemblages from Wardaman Country, located $120 \mathrm{~km}$ southwest of Katherine, Northern Territory. The goal of the study centers on the characterization of diachronic changes in stone tool technology from the late Pleistocene until around $1500 \mathrm{BP}$ to infer regional patterns in subsistence and mobility strategies with respect to shifting climatic conditions in the past.

The book is structured in eight chapters. The first chapter reviews the history of archaeology in northern Australia and the role stone tool played in interpreting past cultural change. Traditionally, stone tools have been seen as static markers of cultural presence. Research has mainly focus on explaining the abrupt change in late Holocene technology (the appearance of formal artifact types including backed artifacts, adzes, and retouched points) with reference to diffusion and cultural affinities. This study attempts to move beyond this traditional framework to: 1) consider stone tools as part of the dynamic process of technological behavior that mediates the interaction between humans and the environment; and, 2) characterize the regional sequence of technological change in Wardaman Country with respect to changes in adaptive strategies in response to the varying conditions of resource distribution from 15,000 BP to the late Holocene.

In Chapter Two, the author does an excellent job at integrating various bodies of theory concerning humanenvironment interaction-commonly labeled under the framework of "behavioral ecology." These include optimal foraging theory, risk management and reduction, tool design, and the organization of technology. Each theoretical framework is summarized and predictions are made in terms of behavioral or technological changes that are expected under shifts in the abundance and distribution of resources in the physical environment. These hypotheses are further operationalized into quantifiable artifact attributes in Chapter Three based on the frameworks of core and flake reduction, blank selection, artifact recycling and discard. The full list of attributes recorded for each artifact is included in the appendix.

Chapter Four reviews the physiographic setting of Wardaman Country with regard to the nature and distribution of climate and resources in the region. In particular, the location of permanent waterholes and the distribution and quality of lithic raw materials are thought to have significant implications for foraging and land-use strategies of past hunter-gatherers. The disjunction and co-occurrence of these two resources are carefully examined. Variation in the distribution of resources across the landscape through time is linked to climatic changes, and the effect of climatic events on the regional environment since the Last Glacial Maximum is considered. Special attention is paid to the long-term El Niño/Southern Oscillation climatic cycle, as it would have had significant impact on the availability and predictability of resources in the region, especially with the onset of ENSO in the later part of Holocene. Chapter Five provides information on the location, strategraphy, and chronology of the four rock shelter sites that are examined in this study. These are Nimji (a.k.a. Ingaladdi), Garnawala 2, Gordolya, and Jagoliya. Three sites contain a continuous sequence of lithic materials from the terminal Pleistocene up to late Holocene, while one site (Jagoliya) contains lithic materials up to an estimated maximum age of 6,500 BP.

Chapter Six presents the reconstructed reduction models of cores and flakes as well as various retouched types including scrapers, adzes, points, and burins. These are supplemented by excellent figures that make the reduction sequences easily understandable. The reconstructed sequence of core reduction (graphically illustrated by the 'event tree,' p.87) is accompanied by relative frequencies of cores representing various stages within the reduction sequence. This is refreshing to see because many present day studies offering reconstructions of past reduction sequences, often employing the analytical framework of chaine opératoire, are largely qualitative descriptions, with little or no quantitative characterization of the reduction process. These reduction models are further related to aspects of tool design such as maintainability, reliability, standardization, transportability, cost of production and repair, and use-life.

Chapter Seven integrates various technological changes observed in the four stone tool assemblages-including artifact discard rate, reduction intensity, technological diversity, raw material use, standardization, and artifact recycling. By tracking these trends with respect to the predictions outlined in Chapter Two, the author successfully translates technological change into behaviorally meaningful patterns that indicate the shifting responses of technology and land-use strategies to changing environmental conditions through time. A regional sequence of humanenvironment interaction from Last Glacial Maximum up to late Holocene is proposed for the Wardaman region. Chap- 
ter Eight then concludes the study by placing the findings within the wider discussion of changes in Aboriginal society, particularly in terms of the interrelationship between stone tools, linguistic boundaries, sociality, and climate.

The merit of Clarkson's study has to be viewed within the broader context of Australian lithic analysis. Stone tool technology in Australia has always been perceived as informal and unchanging. Prior to the appearance of backed artifacts and retouched points in late Holocene, the Australian stone tool industry is characterized by the dominance of flake and core technology, with a limited range of recurring artifact forms and signs of technological standardization. The perceived lack of formal types among retouched tools and their overall infrequent occurrence in lithic assemblages have led to the limited role of typology in Australian lithic analysis. Since the 1960s, early typological frameworks developed by Tindale (e.g., 1941) and McCarthy (1976) gave way to metrical approaches that focus on continuous variation in both retouched and non-retouched artifacts. This shift also was accompanied by increasing ethnographic evidence showing the lack of direct correlation between artifact form and function (White 1969).

Influenced by the advent of the Cambridge school of economic archaeology in the 1960s, this rejection of typology led to a change in research agenda from establishing regional cultural sequence to explaining variability in stone tool attributes in relation to the environment (Holdaway and Stern 2004: 295). By viewing technology as an adaptive response towards the external environment, Australian stone tools were seen to be characterized primarily as maintenance rather than extractive tools (see Binford and Binford 1966). The two-phase pan-continent division of stone tool traditions - the Australian core tool and scraper tradition that characterizes all Pleistocene and early Holocene assemblages containing high proportions of core tool and scrapers, and the Australian small tool tradition which describes late Holocene assemblages possessing a variety of formal implements-further reinforces the static view of Australian technology and culture. While typology still plays a role in describing the retouched component of lithic assemblages, the unchanging nature of stone tool technology for most of Australian prehistory became an established theme in Australian archaeology (Holdaway 1995).

From this perspective, Clarkson's work is significant in its ability to demonstrate technological change in a way that cannot be shown simply by tracking typological changes. Moreover, the integration of multiple technological attributes within a well-established theoretical framework successfully allows the author to arrive at behaviorally meaningful inferences regarding changes in Aboriginal hunter-gatherer adaptive behavior without the need to resort to changes in typological forms. One aspect that receives less attention in the assessment of technology is flake design. The short section on flake variability ( $p$. 136) remains largely unconnected to the wider behavioral context discussed in relation to retouched elements. This is mainly due to the lack of a well-defined theoretical framework for interpreting the variability of unretouched flakes in current day stone tool studies. It is thus welcoming to see the author's recent work (Clarkson and Hiscock 2011) on forwarding the study of basic flake variability in lithic assemblages. The author also discusses briefly the issue of on-site vs. off-site flake production and transport of lithic materials. This aspect is worth further investigation particularly in regarding the import and export of materials, and patterns in flake and tool selection in relation to mobility and subsistence strategies. These observations show that the current study has established a solid basis for more detailed studies that would enrich our understanding of how Wardaman hunter-gatherers interacted with the environment through time.

Another aspect that is worth further discussion is the use of formal versus informal models in the study of human-environment interaction. Clarkson's work, which is characterized by a more informal use of ecological models, contrasts to the recent study by Surovell (2009) where he applied formal models derived from behavioral ecology to Paleoindian lithic assemblage variability. Formal models explicitly abstract from reality. The assumptions allowing for such abstraction and their interrelationship are clearly stated in mathematical forms. The advantage of formal models, thus, is the ability to clearly deduce predictions from the assumptions made. This, however, causes formal models to be less flexible, and the explicitly stated assumptions can be easily criticized as unrealistic. On the other hand, informal models' abstraction from reality is more implicit. Informal models can be conceptualized more easily and applied to various contexts, yet the danger is that the implicit connection between various assumptions can lead to contradictory predictions. It also becomes more difficult to integrate various models and still have predictions logically stated. Clarkson's treatment of the various theories in Chapter Two is comprehensive and clear. However, the lack of formal or explicit relationships between the assumptions made from the various theories would leave the reader wondering if the predictions made do actually map out in the way that it is stated.

To conclude, Clarkson's comprehensive treatment of lithic analysis and reduction sequence will make this volume of interest to a wide range of archaeologists and lithic analysts. The thorough handling of quantitative data within a firm theoretical setting also makes this book a useful guide for interpreting variability in flaked stone tools. The ability to demonstrate change in technological behavior in the absence of typological shift will be compelling for archaeologists who work in the Old World, where the analytical tradition is firmly situated in typology. Clarkson's work thus presents a positive contribution to our understanding of not only Australian prehistory but the analytical potential of flaked stone tools in general.

\section{REFERENCES}

Binford, L.R. and S.R. Binford. 1966. A preliminary analysis of functional variability in the Mousterian of Levallois facies. American Anthropologist 68: 238-295.

Clarkson, C. and P. Hiscock. 2011. Estimating original flake 


\section{BOOK REVIEW ・ 69}

mass from 3D scans of platform area. Journal of Archaeological Science 38(5):1062-1068.

Holdaway, S. 1995. Stone artefacts and the transition. Antiquity 69: 784-797.

Holdaway, S. and N. Stern. 2004. A record in stone: the study of Australia's flaked stone artefacts. Canberra: Aboriginal Studies Press.

McCarthy, F.D. 1976. Australian Aboriginal Stone Implements. 2nd edition. Sydney: Australian Museum.
Surovell, T.A. 2009. Towards a behavioral ecology of lithic technology: cases from Paleoindian archaeology. Tucson: The University of Arizona Press.

Tindale, N.B. 1941. The hand-axe used in the Western Desert of Australia. Mankind 3: 37-41.

White, J.P. 1969. Typologies for some prehistoric flaked stone artefacts of the Australian New Guinea highlands. Archaeology and Physical Anthropology in Oceania 4: $18-46$. 